\title{
Low genetic diversity in the endangered Taxus yunnanensis following a population bottleneck, a low effective population size and increased inbreeding
}

\author{
Y. C. Miao, Z. J. Zhang and J. R. Su \\ Research Institute of Resource Insects, Chinese Academy of Forest (CAF), Kunming, 650233, Yunnan, China \\ * Corresponding author: J.R. Su, Phone: +86-871-63860017, E-mail: jianrongsu@vip.sina.com
}

\begin{abstract}
Taxus yunnanensis, which is an endangered tree that is considered valuable because it contains the effective natural anticancer metabolite taxol and heteropolysaccharides, has long suffered from severe habitat fragmentation. In this study, the levels of genetic diversity in two populations of 136 individuals were analyzed based on eleven polymorphic microsatellite loci. Our results suggested that these two populations were characterized by low genetic diversity $\left(N_{\mathrm{E}}=2.303 / 2.557 ; H_{\mathrm{O}}=\right.$ $\left.0.168 / 0.142 ; H_{\mathrm{E}}=0.453 / 0.517\right)$, a population bottleneck, a low effective population size $(\mathrm{Ne}=7 / 9)$, a high level of inbreeding $\left(F_{1 S}=0.596 / 0.702\right)$, and a weak, but significant spatial genetic structure $\left(S p=0.001, b=-0.001^{*}\right)$. Habitat fragmentation, seed shadow overlap and limited seed and pollen dispersal and potential selfing may have contributed to the observed gene tic structure. The results of the present study will enable development of practical conservation measures to effectively conserve the valuable genetic resources of this endangered plant.
\end{abstract}

Keywords: bottleneck, effective population size ( $\mathrm{Ne}$ ), inbreeding, spatial genetic structure (SGS), Taxus yunnanensis

\section{Introduction}

The genetic diversity of a species is important to its current persistence and long-time evolutionary potential (Anderson et al., 2011). The levels of genetic variation of a species are mainly determined by ecological, demographic, and life history (Nevo et al., 1984). However, recent human-induced habitat fragmentation has had a severely adverse impact on genetic diversity, resulting in decreased population sizes (Martín et al., 2014), reduced effective population sizes (Ne) (Manoel et al., 2012), increased inbreeding (Vu et al., 2016) and the occurrence of strong spatial genetic structure (SGS; Sjölund and Jump, 2015), which can severely reduce within-population genetic diversity and adaptive ability under changing environmental conditions. Thus, understanding the levels of genetic diversity is crucial to developing practical and effective conservation strategies for endangered species.

Taxus yunnanensis is one of six Taxus species in China (Zhang et al., 2012) that is mainly distributed in the southwest region (Fu et al., 1999). This species is a patchily distributed, understory woody gymnosperm that has an extremely high medicinal value because of the presence of taxol and heteropolysaccharides, which are natural anti-cancer substances that are effective for treatment of ovarian, breast and liver cancers (Yin et al., 2010; Hai et al., 2014). In China, a number of natural T. yunnanensis populations have been led to smaller and more isolated populations because of natural habitat fragmentation caused by excessive anthropogenic logging for taxol extraction (Miao et al., 2014). Such fragmentation is likely to increase the negative effects of biparental inbreeding; however, it has been identified as an endangered plant on the national red list of China (State Forestry Bureau, 1999).

In the genus Taxus, sexual formations are complex, including the exclusive monoecious T. canadensis (Wilson et al., 1996), pure dioecious T. wallichiana (Vu et al., 2016) and T. contorta (Poudel et al., 2014) and mixed T. brevifolia (Hogg et al., 1996) and T. baccata (Di Cosmo, 2005). Studies of genetic 
diversity have shown that many exclusive and mixed Taxus species have an especially high level of inbreeding, with $F_{\text {IS }}$ values of 0.226 to 0.472 (El-Kassaby and Yanchuk, 1994; Chung et al., 1999; Myking et al., 2009; Dubreuil et al., 2010; Zhang and Zhou, 2013; Poudel et al., 2014; Vu et al., 2016). T. yunnanensis has long been believed to a strictly dioecious tree; however, cosexuality has recently been confirmed in this species (Wang et al., 2008).

Although it is limited and only based on isoenzymes, present genetic knowledge regarding $T$. yunnanensis indicates that it is on the verge of extinction (Chen et al., 2001). To better understand the levels of genetic diversity in this species, bottleneck, SGS, Ne and inbreeding analyses within two populations were conducted using microsatellite markers. Practical conservation strategies for this endangered species were then proposed based on the results.

\section{Material and Methods}

\section{Study populations and sampling}

Two natural T. yunnanensis populations, TY1 $(n=79$ in a $79 \times 69$ $m$ area; $\left.26^{\circ} 39^{\prime} 10.08^{\prime \prime} \mathrm{N}, 99^{\circ} 36^{\prime} 7.2^{\prime \prime} \mathrm{E}\right)$ and TY2 ( $=57$ in a $132 \times 97$ $\mathrm{m}$ area; $26^{\circ} 27^{\prime} 18.36^{\prime \prime} \mathrm{N}, 99^{\circ} 14^{\prime} 27.24^{\prime \prime} \mathrm{E}$ ) separated by approximately $42 \mathrm{~km}$ and located in Lanping County, Yunnan Province, China were selected for the study (see Table S1). The tree diameter at breast height $(\mathrm{DBH})$ and tree height ranged from 0 to $46.2 \mathrm{~cm}$ and 12.7 to $90.4 \mathrm{~cm}$, with a mean of $11.1 \mathrm{~cm}$ and 44.7 $\mathrm{cm}$, and from 0 to $20 \mathrm{~m}$ and 3 to $20 \mathrm{~m}$, with a mean of $7.4 \mathrm{~m}$ and $10.1 \mathrm{~m}$ in TY1 (four seedlings in TY1) and TY2, respectively. According to the regression equation of the relationship between tree height and tree age $Y=1.09937 \times X^{0.46538}(Y=$ tree age, $X=$ tree height; Wang et al., 2006), the tree age ranged from 0 to $509.6 \mathrm{y}$ and 8.6 to $509.6 \mathrm{y}$, with a mean of $92.6 \mathrm{y}$ and $144.7 \mathrm{y}$ in TY1 and TY2, respectively. Based on the observation of an individual needing 15 years to grow to maturity (Wang et al., 2006), there were approximately $78.48 \%$ and $89.47 \%$ adult individuals in TY1 and TY2, respectively. The relative spatial locations between individuals within each population are shown in Figure 1. Fresh leaves of each individual were collected in separate plastic bags containing silica gel and stored at room temperature prior to DNA extraction.

\section{DNA extraction and microsatellite genotyping}

Extraction of genomic DNA, primer sequences of the 11 polymorphic microsatellites (Miao et al., 2008), polymerase chain reaction (PCR) conditions, and microsatellite genotyping methods were performed essentially as described by Miao et al. (2014).

\section{Data analyses}

Increased linkage disequilibrium (LD) between loci can cause a reduction in Ne because of selection at linked sites (Charlesworth and Wright, 2001); thus LD tests between all pairs of loci
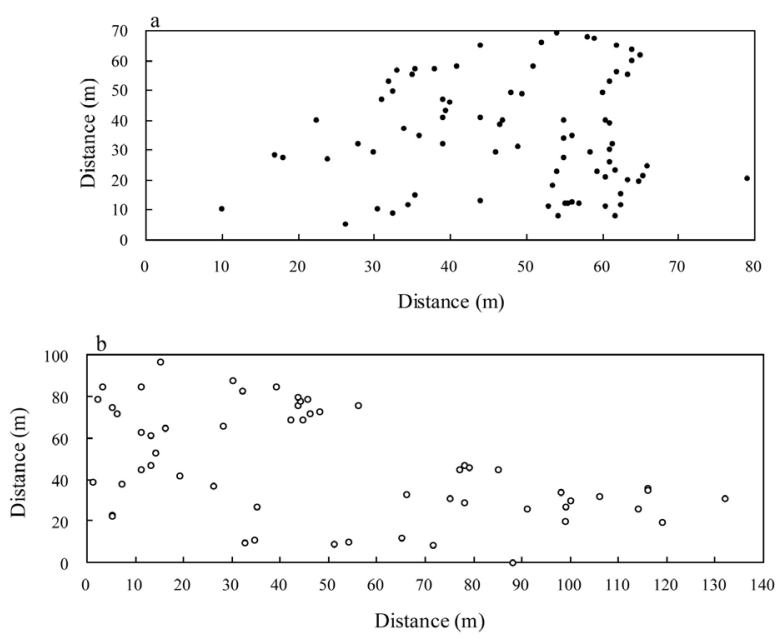

Figure 1

Spatial distribution of Taxus yunnanensis samples collected from TY1 (a) and TY2 (b) populations

were performed using FSTAT v 2.9.3 (Goudet, 1995) to evaluate the independence of loci.

\section{Genetic variation within each population}

INEST $\vee 2.1$ was used to calculate the observed heterozygosity $\left(H_{\mathrm{O}}\right)$, expected heterozygosity $\left(H_{\mathrm{E}}\right)$, inbreeding coefficient $\left(F_{\mathrm{IS}}\right)$ and null frequency $\left(F_{\mathrm{N}}\right)$ of each locus and the mean $F_{\mathrm{IS}}$ of each population with the Markov Chain Monte Carlo (MCMC) based on $5 \times 10^{5}$ cycles, $1 \times 10^{3}$ thinning and $5 \times 10^{4}$ burn-in periods. POPGENE $v 1.31$ was used to calculate the effective number of alleles $\left(N_{\mathrm{E}}\right)$ of each locus. The BOTTLENECK v 1.2.02 (Piry et al., 1999) program was used to infer the presence of demographic expansion/ contraction in each population using the infinite allele model (IAM). The same program was also used to assess the significance of homozygosity excess with $1 \times 10^{4}$ iterations. Finally, the program LDNE (Waples and Do, 2008) was employed to calculate the numbers of $N_{\mathrm{e}}$ and their confidence intervals $(\mathrm{Cl})$ for these two populations.

\section{Structure analyses of each population}

To investigate the individual genetic relationship, viz., the numbers of family structures within each population, the program STRUCTURE v 2.2 (Pritchard et al., 2000) was used. This software calculates the proportion of membership of each individual to the inferred $K$ clusters ( $K=$ number of potential groups). The most likely value of $K$ was the smallest value of $K$ that captured the major structure [maximum value of Ln Prob of Data $(L n P(D)]$ in the data. For both populations, the $K$ range was set from one to 12 (because $K=8$ captured the maximum structure and a range of $K$ of one to 12 clearly showed the data trend). Each simulation consisted of $5 \times 10^{5} \mathrm{MCMC}$ iterations following a burn-in period of $5 \times 10^{5}$ iterations. Ten independent repeats of each $K$ were carried out to quantify the mean amount of $\operatorname{Ln} P(D)$. 


\section{Spatial genetic structure of each population}

To examine the SGS within each population, the kinship coefficient $\left(F_{\mathrm{ij}}\right.$ i Loiselle et al., 1995) was calculated for both populations using SPAGEDI v 1.3 (Hardy and Vekemans, 2002). For each population, 10 distance classes with equal numbers of sample pairs were defined. To visualize the SGS, the multilocus $F_{i j}$ for each distance class was plotted against the corresponding physical distance. Moreover, to quantify the extent of SGS in these two populations, the regression slopes $b$ (Curtu et al., 2015), Sp (Vekemans and Hardy, 2004) and significance of both multilocus $F_{\mathrm{ij}}$ values per distance class and $b$ were also estimated using the SPAGEDI program. Finally, isolation by distance was estimated using GENAIEX v 6.0 (Peakall and Smouse, 2006) by determining the correlation between $F_{\mathrm{ij}}$ and the corresponding spatial geographic distances for the TY1 and TY2 populations.

\section{Results}

\section{Genetic variation within each population}

LD tests revealed 55 possible pairwise comparisons between the eleven loci for both populations that did not show significant linkage disequilibrium $(P>0.05)$. The genetic variation of both populations is shown in Table 1. The $N_{\mathrm{E}}, H_{\mathrm{O}}, H_{\mathrm{E}}$ and $F_{\mathrm{N}}$ ranged from 1.000 to $5.280,0$ to $0.797,0$ to 0.817 and 0.0006 to 0.0025 , with mean values of $2.303,0.168,0.453$ and 0.0018 per locus for TY1, while these values ranged from 1.036 to $6.315,0$ to $0.947,0.035$ to 0.848 and 0.0006 to 0.0024 , with a mean of 2.557, 0.142, 0.517 and 0.0016 per locus for TY2. The inbreeding coefficients were relatively high (up to 1) for most loci, while the mean $F_{\text {IS }}$ reached up to 0.596 and 0.702 for TY 1 and TY2, respectively. The effective population sizes were 7 and 9 , with the bounds of $\mathrm{Cl}$ varying between 4.4 and 10.1, and between 6.5 and 12.3, and estimates of $\mathrm{Ne} / \mathrm{N}$ being 0.09 and 0.16 for TY1 and TY2, respectively. Bottleneck tests showed a significant size reduction in both populations $(P<0.01)$.

\section{Structure analyses for each population}

Structure analyses clearly showed that eight family structures existed in each population (Figure 2). The largest increase break based on the average $\operatorname{Ln} P(D)$ of 10 repeats for $K$ was 8 , with a maximum value of $\operatorname{Ln} P(D)-932.12$ and -791.00 for TY1 and TY2, respectively. The corresponding bar plots for $K=8$ for both populations are shown in Figure 2.

\section{Spatial genetic structure of each population}

Spatial autocorrelation analyses revealed a weak, but significant genetic structure within both populations $(b=-0.001$; Sp $=0.001$ ) (Figure 3). Moreover, the multilocus correlograms showed that significant SGS was apparent when the individual distance was less than $23 \mathrm{~m}$ and $50 \mathrm{~m}$ for the TY1 and TY2 populations, respectively. This was also supported by the structure analyses which identified eight kinship families within each population (Figure 2). In addition, significant and negative linear decreases in the pairwise kinship coefficient $F_{i j}$ with the geographical distance (Figure 4) were detected in TY1 ( $y=$ $-0.001 \mathrm{x}+0.0261 ; P=0.006)$ and TY2 $(\mathrm{y}=-0.0011 \mathrm{x}+0.0547 ; P=$ 0.000 ) populations, indicating that individuals physically close

Table 1

Genetic indices of two natural Taxus yunnanensis populations, TY1 and TY2

\begin{tabular}{|c|c|c|c|c|c|c|c|c|c|c|}
\hline \multirow[b]{2}{*}{ Locus } & \multicolumn{5}{|c|}{ TY1 (79) } & \multicolumn{5}{|c|}{ TY2 (57) } \\
\hline & $N_{\mathrm{E}}$ & $H_{0}$ & $H_{\mathrm{E}}$ & $F_{15}$ & $F_{\mathrm{N}}$ & $N_{E}$ & $H_{0}$ & $H_{E}$ & $F_{\text {is }}$ & $F_{\mathrm{N}}$ \\
\hline TY05 & 2.265 & 0 & 0.566 & 1 & 0.0019 & 2.808 & 0 & 0.655 & 1 & 0.0018 \\
\hline TY08 & 1.568 & 0 & 0.367 & 1 & 0.0024 & 1.407 & 0 & 0.294 & 1 & 0.0018 \\
\hline TY12 & 1.640 & 0 & 0.395 & 1 & 0.0018 & 1.949 & 0 & 0.496 & 1 & 0.0014 \\
\hline TY16 & 1.591 & 0.038 & 0.377 & 0.899 & 0.0019 & 1.693 & 0 & 0.417 & 1 & 0.0013 \\
\hline TY24 & 1.026 & 0 & 0.025 & 1 & 0.0014 & 1.036 & 0 & 0.035 & 1 & 0.0018 \\
\hline TY27 & 1.733 & 0 & 0.428 & 1 & 0.0025 & 2.714 & 0 & 0.643 & 1 & 0.0021 \\
\hline TY29 & 2.522 & 0 & 0.611 & 1 & 0.0025 & 2.940 & 0 & 0.672 & 1 & 0.0020 \\
\hline TY44 & 1.000 & 0 & 0 & 0 & 0 & 1.407 & 0 & 0.294 & 1 & 0.0015 \\
\hline TS07 & 3.860 & 1 & 0.744 & -0.344 & 0.0007 & 6.315 & 0.947 & 0.848 & -0.117 & 0.0006 \\
\hline TB01 & 2.844 & 0.013 & 0.651 & 0.981 & 0.0021 & 2.978 & 0 & 0.676 & 1 & 0.0024 \\
\hline TW01 & 5.280 & 0.797 & 0.817 & 0.024 & 0.0006 & 2.883 & 0.614 & 0.659 & 0.069 & 0.0006 \\
\hline Average & 2.303 & 0.168 & 0.453 & 0.596 & 0.0018 & 2.557 & 0.142 & 0.517 & 0.702 & 0.0016 \\
\hline $\mathrm{Ne}$ & \multicolumn{5}{|c|}{$7(4.4-10.1)$} & \multicolumn{5}{|c|}{$9(6.5-12.3)$} \\
\hline $\mathrm{Ne} / \mathrm{N}$ & \multicolumn{5}{|c|}{0.09} & \multicolumn{5}{|c|}{0.16} \\
\hline$P$-value & \multicolumn{5}{|c|}{$0.00342^{* * *}$} & \multicolumn{5}{|c|}{$0.00806^{* * *}$} \\
\hline
\end{tabular}



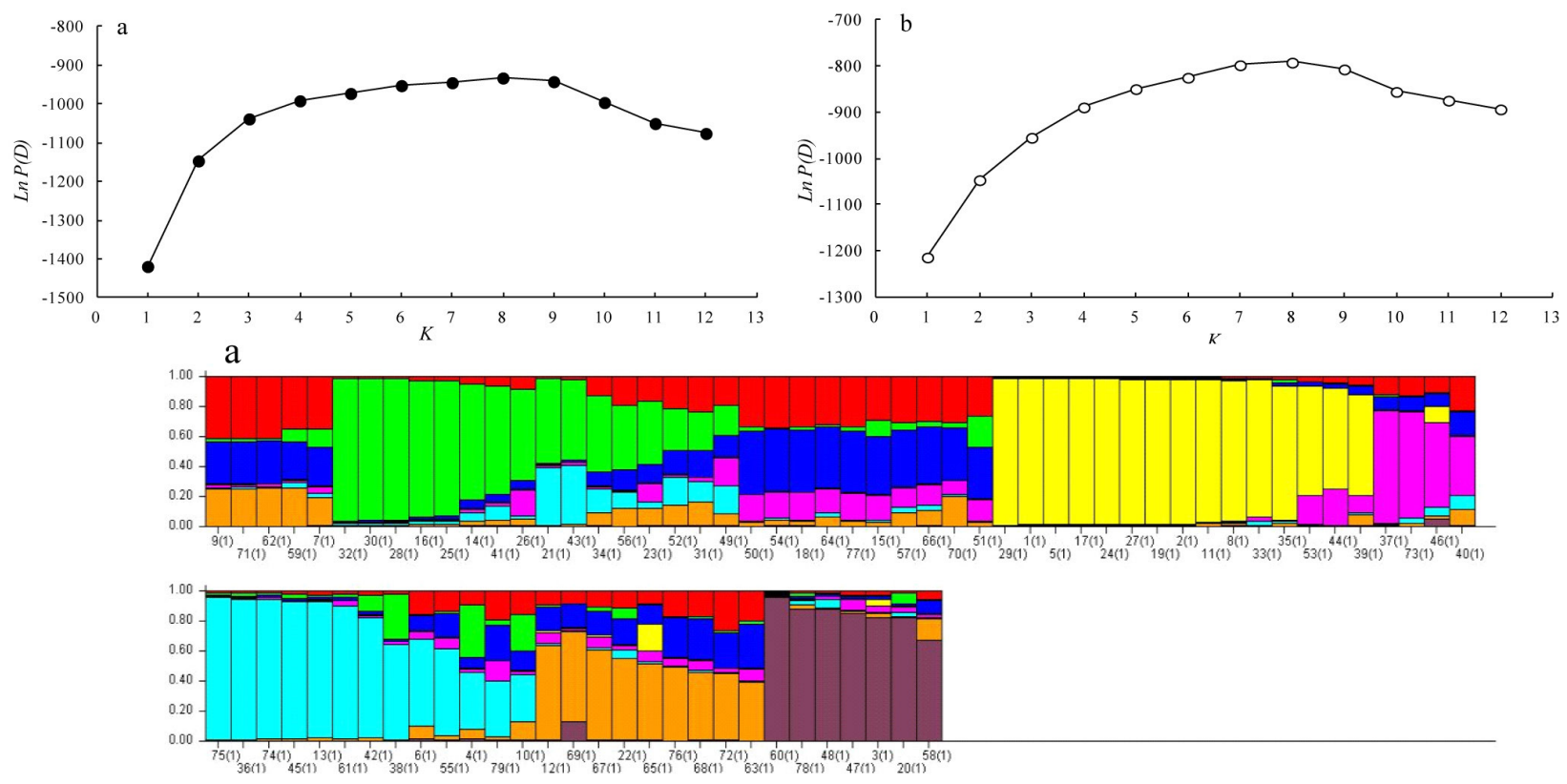

b
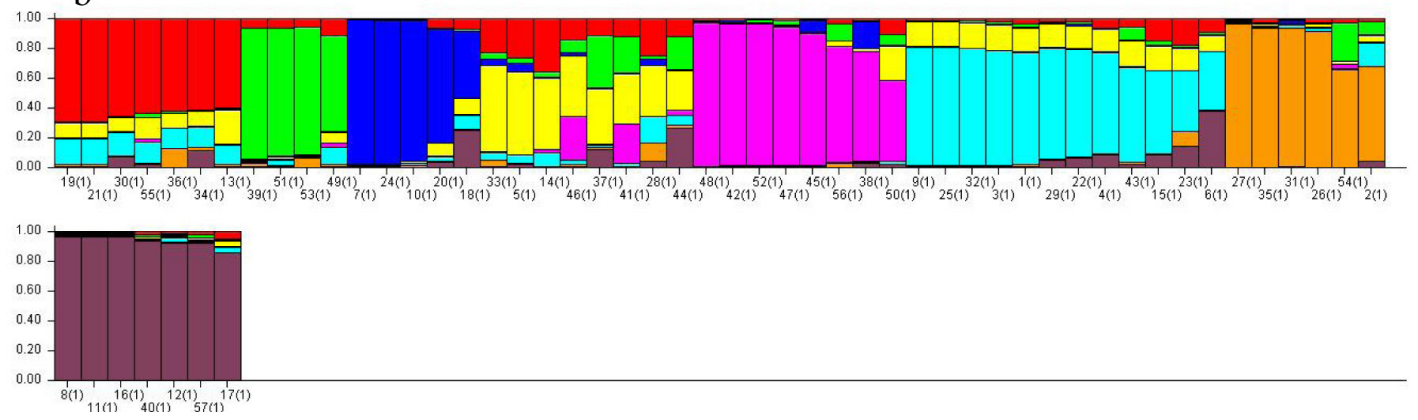

Figure 2

Eight subgroups within the Taxus yunnanensis populations, TY1 (a) and TY2 (b), identified by structure analyses

to each other were more genetically similar than those separated by greater distances.

\section{Discussion}

In this study, the two natural T. yunnanensis populations showed a lower level of genetic diversity than other congener Taxus species $\left(N_{\mathrm{E}}=2.303 / 2.557 ; H_{\mathrm{O}}=0.168 / 0.142 ; H_{\mathrm{E}}=0.453 / 0.517\right.$, Table 1). Evidently, the $N_{\mathrm{E}}$ values were lower than those reported for T. baccata in Poland ( $N_{\mathrm{E}}=6.800$; Chybicki et al., 2011) and T. wallichiana var. mairei $\left(N_{\mathrm{E}}=2.678\right.$; Zhang and Zhou, 2013) from China. The $H_{\circ}$ values were also lower than those reported for T. baccata from the Montseny Mountains in the northeastern Iberian Peninsula $\left(H_{0}=0.487\right.$; Dubreuil et al., 2010) and from Poland ( $H_{\mathrm{O}}=0.624$; Chybicki et al., 2011), as well as those of $T$. wallichiana var. mairei from China $\left(H_{0}=0.390\right.$; Zhang and Zhou, 2013). Moreover, the $H_{\mathrm{E}}$ values were lower than those of T. baccata from the western Mediterranean Basin $\left(H_{\mathrm{E}}=0.660\right.$; González-Martínez et al., 2010), from the Montseny Mountains in the northeastern Iberian Peninsula $\left(H_{\mathrm{E}}=0.622\right.$;
Dubreuil et al., 2010), and from Poland ( $H_{\mathrm{E}}=0.837$; Chybicki et al., 2011), as well as those of $T$. contorta in Pakistan $\left(H_{\mathrm{E}}=0.541\right.$; Poudel et al., 2014) and T. wallichiana var. mairei from China $\left(H_{\mathrm{E}}\right.$ = 0.538; Zhang and Zhou, 2013).

It is not clear why wind-pollinated plants such as T. yunnanensis exhibit such high inbreeding (mean $F_{\mathrm{IS}}=0.596 / 0.702$ ) within populations. Indeed, six Taxus species have been shown to have particularly high levels of inbreeding to date, namely, $T$. baccata $\left(F_{1 S}=0.226 / 0.448\right.$; Myking et al., 2009; Dubreuil et al., 2010), T. chinensis ( $F_{I S}=0.250 ;$ Vu et al., 2016), T. wallichiana $\left(F_{I S}\right.$ $=0.270 / 0.400$; Zhang and Zhou, 2013; Vu et al., 2016), T. contorta $\left(F_{\mathrm{IS}}=0.418\right.$; Poudel et al., 2014), $T$. brevifolia $\left(F_{\mathrm{IS}}=0.472\right.$; ElKassaby and Yanchuk, 1994) and T. cuspidata $\left(F_{15}=0.229\right.$; Chung et al., 1999). Theoretically, high inbreeding could be explained by the presence of null alleles, biparental inbreeding, low $\mathrm{Ne}$ and/or selfing. Null allele frequency analyses have excluded null allele impact on the high inbreeding because of the extremely low frequency of 0.0018 and 0.0016 per locus in TY1 and TY2. In our opinion, the biparental inbreeding, low $\mathrm{Ne}$ and potential selfing may have all contributed to the unexpected 


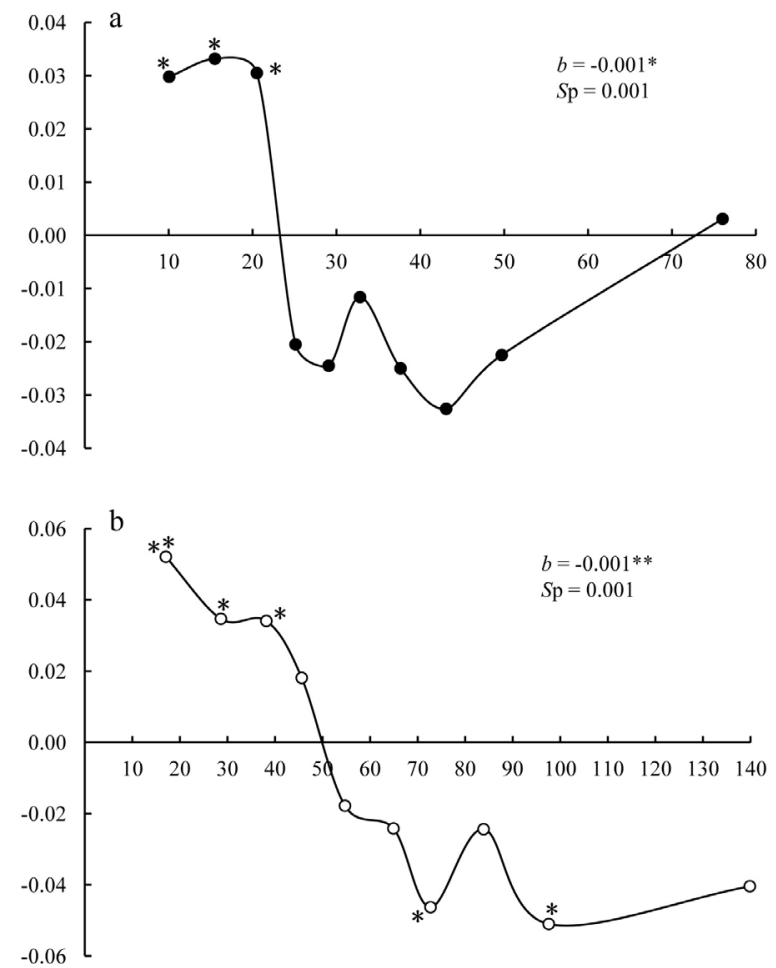

Figure 3

Kinship coefficient $F_{\mathrm{ij}}$ correlograms over 10 distance intervals with equal numbers for the two Taxus yunnanensis populations, TY1 (a) and TY2 (b); ${ }^{*} p<0.05,{ }^{* *} p<0.01$
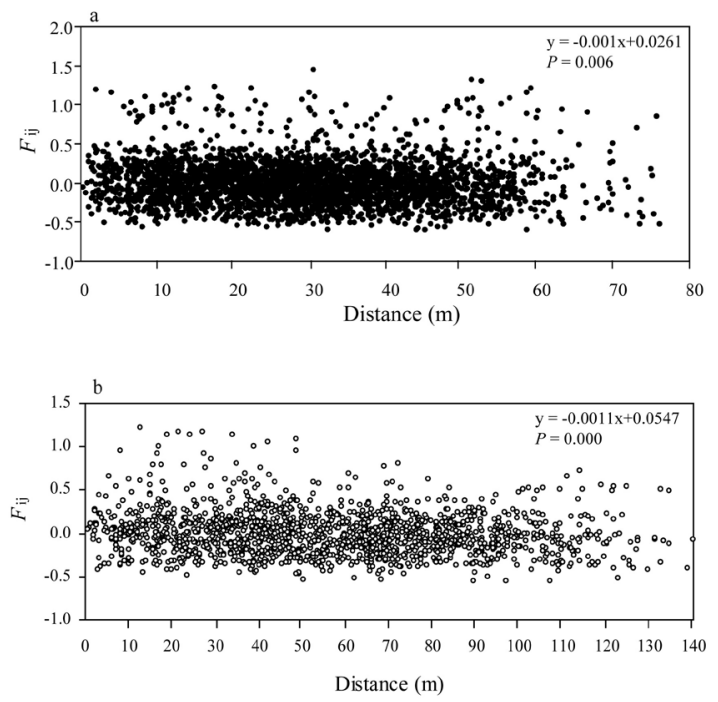

Figure 4

Kinship coefficient $F_{\mathrm{ij}}$ versus spatial geographical distance plots for the Taxus yunnanensis populations, TY1 (a) and TY2 (b) inbreeding. Specifically, biparental inbreeding due to limited seed and pollen dispersal could contribute to the high inbreeding. A recent study showed that severe habitat fragmentation in T. yunnanensis has sharply reduced the population size and increased the level of inbreeding (Miao et al., 2014). In this study, weak but significantly positive $F_{\mathrm{ij}}$ values were found to extend up to $23 \mathrm{~m}$ and $50 \mathrm{~m}$ in both bottlenecked populations, which is consistent with a mechanism of limited seed and pollen dispersal combined with seed shadow overlap that occurs at high adult density (see Study populations and sampling) and a potential male bias within each population (Chybicki et al., 2016). Structure analyses also indicated that eight kinship families existed within each population, suggesting that mating has not been at random within these two populations and that consanguineous matings occurred between genetically related individuals. Limited seed dispersal can be caused by the following two scenarios: when seeds of $T$. yunnanensis mature, they drop directly beneath a maternal tree by gravity, which could lead to clumping of relatives in the vicinity of the mother parent and result in spatial kin-structured patches. Moreover, it is generally believed that birds disperse seeds of this species; however, there is no direct indication that seeds would be especially attractive to birds. Indeed, it is more likely that rodents would have greater interest in seeds of this understory plant than birds; therefore, rodent caches would contribute to the construction of observed kinship families. Thus, it is necessary to determine the proportions of seeds removed by birds versus rodents in a future study (Wilson et al., 1996). Limited pollen flow may also contribute to the occurrence of biparental inbreeding. Although no data regarding the spatial scale of pollen dispersal in natural $T$. yunnanensis were available, long-distance pollen movement was not expected. This is because the species is an understory tree that occurs in areas in which the wind velocity is greatly reduced, resulting in pollen flow being highly spatially restricted. These findings are indirectly supported by investigations of the pollen dispersal scale of $T$. canadensis (Allison, 1990), which revealed that a majority of the pollen dropped to the ground within a few meters of the plant due to low wind-pollination efficiency in the forest. It is also important to consider the effects of territorial pollinators on high inbreeding (Franceschinelli and Bawa, 2000) because of changes in ecological factors. Additionally, the extremely small Ne may have contributed to the emergence of strong inbreeding. This is because the degree of inbreeding was inversely proportional to the $\mathrm{Ne}$ as shown by the equation $\mathrm{Ne}=N / 1+F_{\text {IS }}$ (Pollak, 1987). Past intensive felling has undoubtedly reduced the pollen donors and seed-producing females, increasing the relative individual mating. In the present study, the low number of Ne of 7 and 9 for TY1 and TY2, respectively, likely contributed to the high inbreeding. Finally, potential selfing may also contribute to the presence of high inbreeding. Cosexual individuals of $T$. yunnanensis have been discovered (Wang et al., 2008), despite being listed as exclusively diecious, which may be a response to ecology constraints of limited pollen availability (Wilson et al., 1996). Considering the understory properties, the wind might be less efficient; accordingly, it is 
possible that the monoecious individuals are becoming favored. Once selfing occurs, the inbreeding would increase.

Estimates of $\mathrm{Ne}$ are fundamental to understanding population structure, genetic conservation and evolutionary potential for endangered species such as T. yunnanensis. In the present study, the numbers of Ne were found to be very small for both populations (7 for TY1 and 9 for TY2). These values were significantly lower than 50 , which is considered the threshold at which species are vulnerable to the immediate effects of inbreeding depression (Mace and Lande, 1991). Moreover, the Ne to $N$ ratios of these two populations were only 0.09 and 0.16 , respectively, which were both close to that of the 0.11 averaged across 102 animal and plant species (Frankham, 1995), but below the Mace-Lande' endangerment criteria of 0.2 (Mace and Lande, 1991). Consequently, the rate of loss of genetic variation of endangered $T$. yunnanensis may be more rapid than previously believed. there are two possible explanations for the Ne value being below the census population numbers in these two populations. One is the unequal sex ratios. Although studies conducted by Litkowiec et al. (2015) revealed that the biased sex ratios of 32-68\% females between $T$. baccata populations had no effect on the assessment of genetic diversity, the potential extremely low percentage of females within a T. yunnanensis population would consistently support the results of a study by Frankham (1995) in which unequal sex ratios were found to greatly reduce $\mathrm{Ne}$ to below the actual population size. However, it was difficult for us to find microand macro-strobili to enable accurate determination of the sex for many trees in these two populations because they were too high to reach (>10.0 m, see Table S1). Nevertheless, the potential overwhelming male-biased sex ratio occurrence due to environmental stress (Ortiz et al., 2002) in both populations was indirectly confirmed by the results observed in other natural populations. For instance, Wang et al. (2006) reported that the average sex ratio of females to males was 1:3. Moreover, $\mathrm{Li}$ et al. (2005) detected smaller ratios of females to males in two natural Lijiang populations, with ratios of 1:34 and 0:14, respectively. The other possible explanation is variance in fecundity. Wang et al. (2006) reported that the seed set of a T. yunnanensis tree was positively correlated with the sunlight intensity, varying from $7 \mathrm{~kg}$ to $20 \mathrm{~g}$. This species is usually distributed in the undergrowth of coniferous and broadleaved mixed forests (Miao et al., 2014). In general, individuals with marginal growth tended to produce more seeds than those with central growth. Thus, different individuals sharing different sunlight intensities would not have the same progeny production.

In summary, the two natural T. yunnanensis populations investigated in this study were characterized by low genetic diversity following a population bottleneck, weak but significant SGS, extremely low effective population size and high inbreeding. To effectively conserve the genetic diversity of this species to maintain the adaptive potential under changing environmental conditions, in situ and ex situ conservation should be implemented (Miao et al., 2015), especially for the actual breeding individuals ( $\mathrm{Ne}$ ). Moreover, increasing the $\mathrm{Ne}$ can not only promote the quantity of expected heterozygosity $(H \mathrm{t})$, but also decrease the degree of inbreeding within a population based on the equation $\mathrm{Ht} / \mathrm{Ho}=[1-\mathrm{l} /(2 \mathrm{Ne})]^{\mathrm{t}}=1-\mathrm{F}$ given by Falconer (1989). Thus, we should try to increase the number of actual breeding individuals with different genetic representations to maximize the genetic variation within a population. Greater attention should also be paid to seed dormancy mechanisms. Miao et al. (2015) found that individuals established by seed propagation had greater genetic diversity and contained more unique alleles than those that were vegetatively propagated. Similarly, Yang et al. (2011) reported that the former tended to have greater numbers of prosperous roots, straighter trunks and stronger disease resistance than the latter. However, the seed germination of T.yunnanensis has been a challenge because of its deep dormancy, which leads to a small number of seeds germinating only after experiencing dormancy in soil for about 15 months to eliminate dormant factors (Bian et al., 2015). The most important step is to understand which component(s) of T.yunnanensis seeds, testa, endosperms and embryos, separately or jointly, contribute to seed dormancy. Once this information is obtained, the seed germination rates will likely be greatly improved (Blumenthal et al. 1986). Finally, deliberate augmentation of the gene flow within and between populations is also essential to this small, isolated and inbred species (Frankham, 2015).

\section{Acknowledgements}

This work was supported by the National Natural Science Foundation of China (grant number 31470617).

\section{References}

Allison, TD (1990) Pollen production and plant density affect pollination and seed production in Taxus canadensis. Ecology 71(2):516-522. Available at https://doi.org/10.2307/1940305

Anderson, JT, Willis JH, Mitchell-Olds T (2011) Evolutionary genetics of plant adaptation. Trends in Genetics 27(7):258-266. Available at https://doi. org/10.1016/j.tig.2011.04.001

Bian, FY, Su JR, Liu WD, Li SF, Lang XD (2015) The morphology of fresh seeds and germination of in vitro embryos for Taxus yunnanensis. Acta Ecol Sin 35(24):1-10. Available at https://doi.org/10.5846/stxb201406081180

Blumenthal, A, Lerner HR, Werker E, Poljakoff-Mayber A (1986) Germination preventing mechanisms in Iris seeds. Ann Bot-London 58(4):551-561. Available at https://doi.org/10.1093/annbot/58.4.551

Charlesworth, D, Wright SI (2001) Breeding systems and genome evolution. Curr Opin Genet Dev 11(6):685-690. Available at https://doi.org/10.1016/s0959437x(00)00254-9

Chen, SY, Wu LY, Li JW, Xiang W, Zhou Y (2001) Study on genetic diversity of nature populations of Taxus yunnanensis. Scientia Silvae Sinicae 37(5):41-48.

Chung, MG, Oh GS, Chung JM (1999) Allozyme variation in Korean populations of Taxus cuspidata (Taxaceae). Scand J Forest Res 14(2):103-110. Available at https://doi.org/10.1080/02827589950152827

Chybicki, IJ, Dering M, Iszkuło G, Meyza K, Suszka J (2016) Relative strength of fine-scale spatial genetic structure in paternally vs biparentally inherited DNA in a dioecious plant depends on both sex proportions and pollen-toseed dispersal ratio. Heredity 117:449-459. Available at https://doi. org/10.1038/hdy.2016.65

Chybicki, IJ, Oleksa A, Burczyk J (2011) Increased inbreeding and strong kinship structure in Taxus baccata estimated from both AFLP and SSR data. Heredity 107(6):589-600. Available at https://doi.org/10.1038/hdy.2011.51 
Curtu, AL, Craciunesc I, Enescu CM, Vidalis A, Sofletea N (2015) Fine-scale spatial genetic structure in a multi-oak-species (Quercus spp.) forest. iForest 8:324332. Available at https://doi.org/10.3832/ifor1150-007

Di Cosmo, L (2005) Confirmation of cosexuality in Taxus baccata L. Ital J Forest Mt En 60(5):641-650.

Dubreuil, M, Riba M, González-Martínez SC, Vendramin GG, Sebastiani F, Mayol M (2010) Genetic effects of chronic habitat fragmentation revisited: Strong genetic structure in a temperate tree, Taxus baccata (Taxaceae), with great dispersal capability1. Am J Bot 97(2):303-310. Available at https://doi. org/10.3732/ajb.0900148

El-Kassaby, YA, Yanchuk AD (1994) Genetic diversity, differentiation, and inbreeding in Pacific yew from British Columbia. J Hered 85(2):112-117. Available at https://doi.org/10.1093/oxfordjournals.jhered.a111407

Falconer, DS (1989) Introduction to quantitative genetics. Longman Scientific \& Technical, New York. 3rd ed. 438p.

Franceschinelli, EV, Bawa KS (2000) The effect of ecological factors on the mating system of a South American shrub species (Helicteres brevispira). Heredity $84: 116-123$. Available at https://doi.org/10.1046/j.13652540.2000.00636.x

Frankham, R (1995) Effective population size/adult population size ratios in wildlife: a review. Genet Res 66(2):95-107. Available at https://doi. org/10.1017/s0016672300034455

Frankham, R (2015) Genetic rescue of small inbred populations: meta-analysis reveals large and consistent benefits of gene flow. Mol Ecol 24(11):26102618. Available at https://doi.org/10.1111/mec.13139

Fu, LG, LiN, Mill RR (1999) Taxaceae. Flora of China 4:89-96.

González-Martínez, SC, Dubreuil M, Riba M, Vendramin GG, Sebastiani F, Mayol M (2010) Spatial genetic structure of Taxus baccata $L$. in the western Mediterranean Basin: Past and present limits to gene movement over a broad geographic scale. Mol Phylogenet Evol 55(3):805-815. Available at https:// doi.org/10.1016/j.ympev.2010.03.001

Goudet, J (1995) FSTAT( Version 1.2): a computer program to calculate F-statistics. J Hered 86(6):485-486. Available at https://doi.org/10.1093/oxfordjournals.jhered.a111627

Hai, P, Wen SZ, Li Y, Gao Y, Jiang XJ, Wang F (2014) New Taxane Diterpenoids from Taxus yunnanensis. Nat Prod Biop 4(1):47-51. Available at https://doi. org/10.1007/s13659-014-0003-9

Hardy, OJ, Vekemans X (2002) SPAGeDi: a versatile computer program to analyse spatial genetic structure at the individual or population levels. Mol Ecol Notes 2(4):618-620.

Hogg, KE, Mitchell AK, Clayton MR (1996) Confirmation of cosexuality in Pacific yew (Taxus brevifolia Nutt.). Great Basin Nat 56(4):377-378.

Li, LF, Zhou Y, Wang DM (2005) Analysis of the endangered causes of Taxus yunnanensis. Journal of West China Forestry Science 34(3):30-34.

Litkowiec, M, Plitta-Michalak BP, Lewandowski A, Iszkuło G (2015) Homogenous genetic structure in populations of Taxus baccata with varied proportions of male and female individuals. Silva Fenn 49(4):id 1236. Available at https:// doi.org/10.14214/sf.1236

Loiselle, BA, Sork VL, Nason J, Graham C (1995) Spatial genetic structure of a tropical understory shrub, Psychotria officinalis (Rubiaceae). Am J Bot 82(11):1420-1425. Available at https://doi.org/10.2307/2445869

Mace, GM, Lande R (1991) Assessing extinction threats: towards a reevaluation of IUCN threatened species categories. Conserv Biol 5(2):148-157. Available at https://doi.org/10.1111/j.1523-1739.1991.tb00119.x

Manoel, RO, Alves PF, Dourado CL, Gaino PSC, Freitas MLM, Moraes MLT, Sebbenn AM (2012) Contemporary pollen flow, mating patterns and effective population size inferred from paternity analysis in a small fragmented population of the Neotropical tree Copaifera langsdorffii Desf. (Leguminosae-Caesalpinioideae). Conserv Genet 13(3):613-623. Available at https:// doi.org/10.1007/s10592-011-0311-0

Martín, MA, Mattioni C, Lusini I, Molina JR, Cherubini M, Drake F, Herrera MA, Villani F, Martín LM (2014) New insights into the genetic structure of Araucaria araucana forests based on molecular and historic evidences. Tree Genet Genom 10(4):839-851. Available at https://doi.org/10.1007/s11295-014$\underline{0725-1}$

Miao, YC, Lang XD, Zhang ZZ, Su JR (2014) Phylogeography and genetic effects of habitat fragmentation on endangered Taxus yunnanensis in southwest China as revealed by microsatellite data. Plant Biology 16(2):365-374. Available at https://doi.org/10.1111/plb.12059
Miao, YC, Su JR, Zhang ZJ, Lang XD, Liu WD, Li SF (2015) Microsatellite markers indicate genetic differences between cultivated and natural populations of endangered Taxus yunnanensis. Bot J Linn Soc 177(3):450-461. Available at https://doi.org/10.1111/boj.12249

Miao, YC, Su JR, Zhang ZJ, Li H, Luo J, Zhang YP (2008) Isolation and characterization of microsatellite markers for the endangered Taxus yunnanensis. Conserv Genet 9(6):1683-1685. Available at https://doi.org/10.1007/s10592$\underline{008-9532-2}$

Myking, T, Vakkari P, Skrøppa T (2009) Genetic variation in northern marginal Taxus baccata L. populations. Implications for conservation. Forestry 82(5):529-539. Available at https://doi.org/10.1093/forestry/cpp022

Nevo, E, Beiles A, Ben-Shlomo R (1984) The evolutionary significance of genetic diversity: ecological, demographic and life history correlates. Lect Notes Biomath 53:13-213. Available at https://doi.org/10.1007/978-3-642-51588$\underline{0 \_} 2$

Ortiz, PL, Arista M, Talavera S (2002) Sex ratio and reproductive effort in the dioecious Juniperus communis subsp. alpina (Suter) Čelak. (Cupressaceae) along an altitudinal gradient. Ann Bot-London 89(2):205-211. Available at https://doi.org/10.1093/aob/mcf028

Peakall, ROD, Smouse PE (2006) GENALEX 6: genetic analysis in Excel. Population genetic software for teaching and research. Mol Ecol Notes 6(1):288-295. Available at https://doi.org/10.1111/j.1471-8286.2005.01155.x

Piry, S, Luikart G, Cornuet JM (1999) Bottleneck: a computer program for detecting recent reductions in the effective population size using allele frequency data. J Hered 90(4):502-503. Available at https://doi.org/10.1093/ jhered/90.4.502

Pollak, E (1987) On the theory of partially inbreeding populations. I. Partial selfing. Genetics 117(2):353-360.

Poudel, RC, Möller M, Li DZ, Shah A, Gao LM (2014) Genetic diversity, demographical history and conservation aspects of the endangered yew tree Taxus contorta (syn. Taxus fuana) in Pakistan. Tree Genet Genom 10(3):653-665. Available at https://doi.org/10.1007/s11295-014-0711-7

Pritchard, JK, Stephens M, Donnelly P (2000) Inference of population structure using multilocus genotype data. Genetics 155(2):945-959.

Sjölund, MJ, Jump AS (2015) Coppice management of forests impacts spatial genetic structure but not genetic diversity in European beech (Fagus sylvatica L.). For Ecol Manag 336(15):65-71. Available at https://doi.org/10.1016/j. foreco.2014.10.015

State Forestry Bureau (1999) A list of key wild plants under state protection. Available at http://www.gov.cn/gongbao/content/2000/content_60072. htm.

Vekemans, X, Hardy OJ (2004) New insights from fine-scale spatial genetic structure analyses in plant populations. Mol Ecol 13(4):921-935. Available at https://doi.org/10.1046/j.1365-294x.2004.02076.x

Vu, DD, Bui TTX, Nguyen MT, Vu DG, Nguyen MD, Bui VT, Huang X, Zhang Y (2016) Genetic diversity in two threatened species in Vietnam: Taxus chinensis and Taxus wallichiana. J For Res DOI: 10.1007/s11676-016-0323-1. Available at https://doi.org/10.1007/s11676-016-0323-1

Wang, BY, Su JR, Fernando DD, Yang ZH, Zhang ZJ, Chen XM, Zhang YP (2008) Development of the male reproductive structures in Taxus yunnanensis. Plant Syst Evol 276(1):51-58. Available at https://doi.org/10.1007/s00606$\underline{008-0079-y}$

Wang, WB, Jiang YB, Wang DM, Zhou Y, Jing YB (2006) Biological and ecological characteristics of Taxus yunnanensis. Journal of West China Forestry Science 35(4):33-39.

Waples, RS, Do C (2008) LDNE: a program for estimating effective population size from data on linkage disequilibrium. Mol Ecol Resour 8(4):753-756. Available at https://doi.org/10.1111/j.1755-0998.2007.02061.x

Wilson, $\mathrm{P}$, Buonopane M, Allison TD (1996) Reproductive biology of the monoecious clonal shrub Taxus canadensis. Bull Torrey Bot Club 123(1):7-15. Available at https://doi.org/10.2307/2996301

Yang, L, Chen HG, Niu ZL, Shi WY (2011) A preliminary study on the seed dormancy breaking effect of germination soaking methods on Taxus yunnanensis. Hubei Agricultural Sciences 50(10):2057-2059.

Yin, Y, Yu RM, Yang W, Yuan F, Yan CY, Song LY (2010) Structural characterization and anti-tumor activity of a novel heteropolysaccharide isolated from Taxus yunnanensis. Carbohydr Polym 82(3):543-548. Available at https://doi. org/10.1016/j.carbpol.2010.04.038 
66 Miao et al. S Silvae Genetica (2016) 65-1, 59-66

Zhang, DQ, Zhou N (2013) Genetic diversity and population structure of the endangered conifer Taxus wallichiana var. mairei (Taxaceae) revealed by Simple Sequence Repeat (SSR) markers. Biochem Syst Ecol 49(13):107-114. Available at https://doi.org/10.1016/j.bse.2013.03.030

Zhang, J, Yang CF, Yuan K (2012) Simultaneous Determination of 10-Deacetylbaccatin III, Cephalomannine and Taxol in Different Parts of Taxus Media with Different Growth Years by UPLC. Appl Mech Mater 108:326-330. Available at https://doi.org/10.4028/www.scientific.net/amm.108.326 